Spreadbury: Dietary Refinement and Upper Gut Microbiota

\title{
Dietary Refinement And The Upper Gut Microbiota: The Starting Point For Obesity And Non- Communicable Diseases?
}

\author{
Ian Spreadbury $\mathrm{PhD}$ \\ Montreal, Canada \\ ian.spreadbury@mail.mcgill.ca
}

\section{Introduction}

The epidemics of obesity and related non-communicable diseases remains a matter of the utmost concern for public health(1). While physical exercise has been shown able to provide concrete benefits(2,3), there is good reason to believe that it cannot fully compensate for the deleterious changes produced by poor diet(4). Opinions regarding optimal diet increasingly show elements of convergence, especially regarding the association of dietary refinement and ultra-processed foods with poorer health outcomes(5). Some proposed mechanisms underlying this epidemiology of junk food include the removal from diet of health-promoting compounds due to inadequate fruit and vegetable consumption(6), and the enhancement of glycemic responses by the refinement of foods(7-9). Consistent with the latter, ad libitum low-carbohydrate diets ( $<50 \mathrm{~g} /$ day) have been shown to produce weight loss $(10,11)$ and improve cardiovascular risk profiles(12). However, some very high carbohydrate diets have also been shown to be compatible with population-wide optimal metabolic health in non-cereal agrarian populations(13-16). Likewise, the "paleolithic style" diets used to date in small clinical trials have achieved consensus diet-beating improvements in metabolic and cardiovascular-disease risk factors(17-21) despite not restricting total carbohydrate into the $<50 \mathrm{~g} / \mathrm{day}$ range. Similar short-term benefits have also been shown for "the McDougall Program" a low fat, high carbohydrate diet that places a strong emphasis on food quality and minimizes processed carbohydrates(22). This wide range of carbohydrate content for ad libitum diets that produce weight loss suggests that low glycemic index and minimized insulin release are not credible explanations for their effects, especially in light of the experimental variability in the glycemic index of foods between individuals and between meal contexts(23). However, one factor that these dietary regimens do have in common is minimal consumption of processed foods, milled flours and sugar. The present article is an outline of a recently proposed mechanism $(24,25)$ that could explain the effects of food-quality upon weight and health, independent of overall macronutrient composition.

\section{The Gastrointestinal Microbiota and the Immune System}

The gastrointestinal microbiota has recently been cast as a central player in the etiology of many disease processes, including obesity(26-29). The microbiota has been found to be required for almost all animal models of obesity(30), and may play a role in the vagal and hypothalamic inflammation that accompanies leptin resistance, hyperphagia and the onset of overweight in susceptible animals(31-36). Microbial transplants have been shown able to transfer the phenotypes of both overweight and liver pathology / altered blood sugar regulation to lean germ-free mice, suggesting a potentially causal role of bacteria(37-39). Furthermore, levels of T regulatory immune cells have been found to drop during obesity, while transplant of purified Foxp3(+) T cells from lean to obese animals has produced a protective effect regardless of continued obesogenic diet, indicating a potential immune system involvement in the causal chain of obesity(40). The integrity of the intestinal barrier may also play a role in the development of an obese phenotype. An "aggressive microbiota" (showing increased encroachment through the mucus layer) found in TLR5-/- or emulsifier-fed mice produced overweight and colitis, which could be transferred by microbial transplant to germ-free controls(41). Similar increases in body weight were produced by selective knock-outs of brush border alkaline phosphatase, an enzyme on the intestinal lining that breaks down microbial products(42). These effects could be reversed by the addition of the missing enzyme to food. Such animal models suggest that the ability of 
microbial products to traverse the gut barrier - perhaps to the immune surveillance of the gutassociated lymphoid tissue, may be a key determinant of the development of obesity and metabolic issues $(36,43)$.

\section{Microbes as Sensors of Dietary Refinement - Dental and Systemic Health}

It has long been observed that oral and systemic health are correlated, to the extent that dental treatments have on occasion been marketed as a means to influence cardiovascular disease risk(44). Prior to the advent of farming, dental caries were rare $(45,46)$. The human oral microbiota used to be substantially more diverse, but with the agricultural and industrial revolutions it underwent two major ecosystem shifts introducing the microbes associated with periodontal disease and caries respectively, with flour and sugar implicated in these shifts(47). An inappropriate innate immune response to these microbial changes is believed to underlie periodontitis, and may also exacerbate atherosclerosis $(48,49)$, while limiting the sources of processed carbohydrate in diet can produce marked improvements in periodontal health $(50,51)$. The small intestinal microbiota is proximal to both the satiety-sensing vagal afferents believed to play a key role in energy-homeostasis(52)(35), and to the immune system hub of the gut-associated lymphoid tissue $(53,54)$. Hence, pro-inflammatory microbial ecosystem changes in the small intestine, analogous to those reported in the mouth, and likewise produced by powdered carbohydrates, would be an excellent candidate mechanism to initiate obesity, metabolic syndrome and a wide range of systemic immune dysregulatory effects(24). Such an interaction might explain the adverse impacts of food processing and dietary refinement on health, and how macronutrient-diverse diets can apparently reverse many of these effects by removing foods that may functionally resemble a bacterial growth medium.

\section{Obesity as a Process of Sensitization}

It has been observed that long term weight loss after the onset of obesity is a rare exception(55). Those attempting to calorically restrict Western diets appear to defend their elevated weight, indicating that obesity is a disruption of energy homeostasis(56). Low-carbohydrate(11), Paleolithic (57,58) and McDougall(22) style diets each produce ad libitum weight loss, indicating that these dietary styles produce a rectification of that body weight set-point, likely by restoring leptin sensitivity. It is a common anecdotal observation that formerly obese persons following such diets appear to remain sensitized to elements of the standard Western diet, and must remain adherent to their new way of eating or return to overweight. Indeed it is similarly observed that relief from diverse long-term symptoms and conditions in the non-obese achieved via such diets is also adherence-dependent. These observations of a 'memory' of the problems caused by elements of Western diet may be pertinent to the proposed microbial/immune mechanism, in that adaptive immunity is a candidate mechanism for persisting sensitivity to a process despite its prolonged absence. This raises the possibility that what precludes a return to eating refined or processed foods, even after extended adherence to a diet of elevated food quality, may be an immunological memory of elements of a gut microbial ecosystem promoted by the refined Western diet. Figure 1 shows a schematic overview of the effects of this proposed sensitization process to refined foods. 


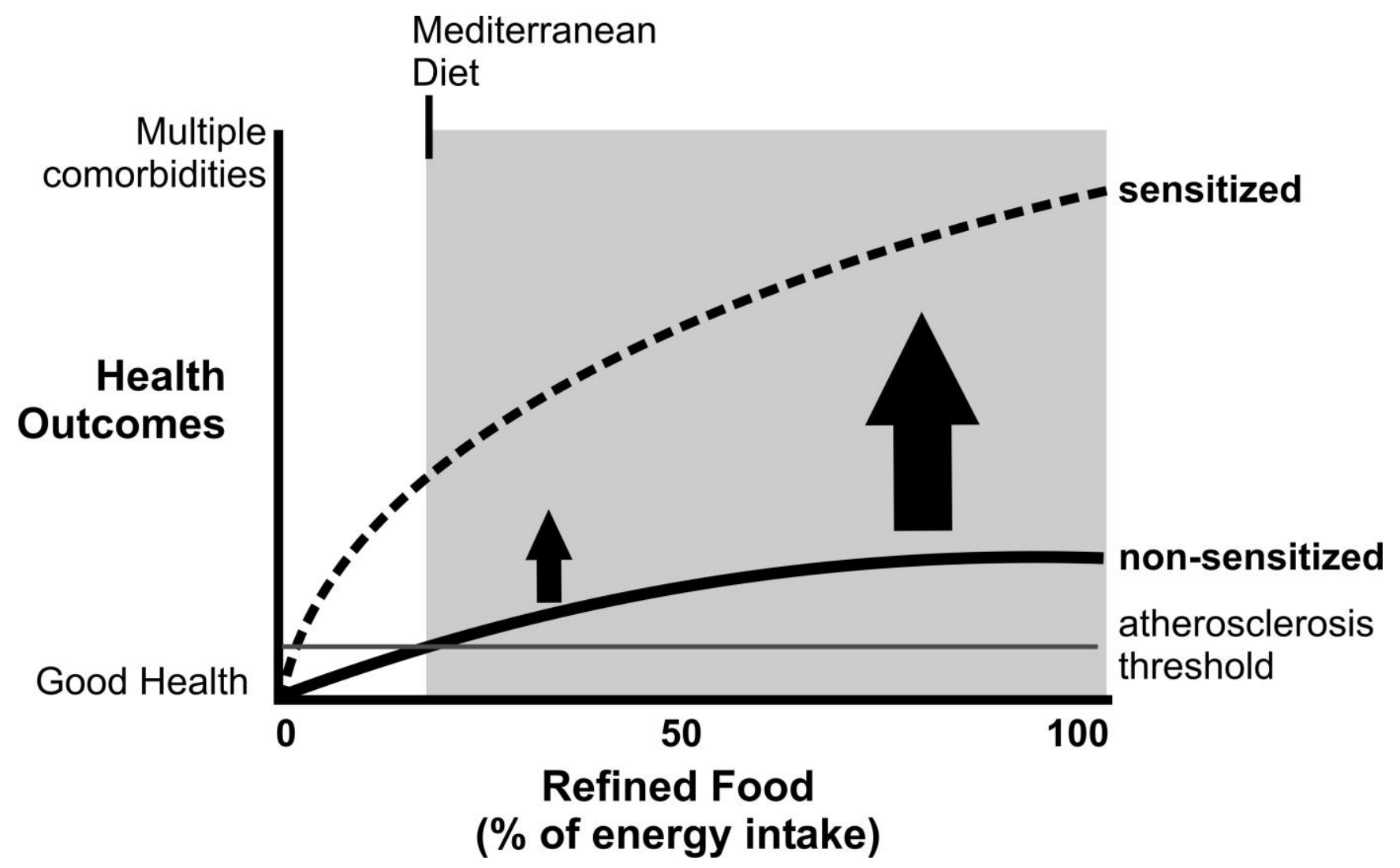

Figure 1. Overview of the proposed effects of sensitization to refined foods. The $\mathrm{x}$-axis represents the proportion of refined foods in diet, while the y-axis depicts the resultant health outcomes. It is proposed that people begin on the 'non-sensitized' curve (solid black). The arrows represent an increasing risk of transitioning to the 'sensitized' curve (dotted black) with exposure to higher proportions of refined foods in diet (this assumption has been included due to the worsening of Western diseases as dietary refinement has increased). Health outcomes are worse in the 'sensitized' than the 'non-sensitized' at any level of exposure to refined foods. This is based upon the anecdotal accounts of those in long term remission from obesity and other Western diseases by eating ad libitum without refined foods, and the degree of strictness often required. It is proposed that there are likely many different degrees and natures of sensitization possible, which may predispose toward diverse Western diseases, however, here one 'sensitized' curve is shown for clarity. The approximate location of a Mediterranean diet is indicated. The threshold for atherosclerosis (grey line) is placed on the assumption that a Mediterranean diet will halt atherosclerosis in the non-sensitized. The grey box depicts the range of dietary refinement tested by the overwhelming majority of dietary research.

Consensus dietary advice places considerable emphasis on the inclusion of breads and baked goods, and it is arguable that this retention of flour-derived foods may be responsible for the poor consensus performance versus paleolithic diets in the clinical trials carried out to date $(17-21,58,59)$. The omnipresence of flour, breads and baked goods in most nutrition research has prevented the proper investigation of the concentration-health relationship for refined foods in 'sensitized' populations, which anecdotal observations from those eating no refined foods indicate may be non-linear.

While overall levels of dietary fat do not appear to be strongly linked to body weight(11), it cannot be ruled out that for some people a sensitization to microbial changes produced by refined fats / oils may 
develop over time and play a clinically relevant role. Perhaps this possibility of a role of 'fat quality' and the bio-structural context of consumed lipids should be borne in mind by those eating low carbohydrate / high fat diets.

\section{Summary}

The interplay between foods altered by human ingenuity and the microbial ecosystem of the upper gastrointestinal tract is an excellent candidate mechanism to explain the effects of human nutrition transitions over the last 10,000 years, and the epidemics of obesity and non-communicable disease. Diets with widely differing macronutrient ratios and differing core principles (low-carbohydrate(11), Paleolithic(57,58) and plant-based McDougall(22)) might produce their ad libitum weight loss by removing more refined / processed foods than achieved by the consensus Mediterranean / DASH diets. By removing evolutionarily novel powdered carbohydrates from the mouth and upper GI tract, these diets may enable a more evolutionarily consistent microbial ecosystem, allowing more accurate energy homeostasis and immune regulation, alongside parallel improvements to oral health.

\section{Acknowledgements and Disclosures}

IS has received speaking expense support from The Ancestral Health Society, The Ancestral Health Society of New Zealand, and Kostreform for Bedre Helse (Norway).

1. Seidell JC, Halberstadt J. Obesity: The obesity epidemic in the USA - no end in sight? Nat Rev Endocrinol [Internet]. 2016 Sep;12(9):499-500.

2. Anderson L, Oldridge N, Thompson DR, Zwisler A-D, Rees K, Martin N, et al. Exercise-Based Cardiac Rehabilitation for Coronary Heart Disease: Cochrane Systematic Review and Meta-Analysis. J Am Coll Cardiol [Internet]. 2016 Jan 5 [cited 2016 Oct 9];67(1):1-12.

3. Wilson MG, Ellison GM, Cable NT. Basic science behind the cardiovascular benefits of exercise. Br J Sports Med [Internet]. 2016 Jan [cited 2016 Oct 9];50(2):93-9.

4. Malhotra A, Noakes T, Phinney S. It is time to bust the myth of physical inactivity and obesity: you cannot outrun a bad diet. Br J Sports Med. 2015;0(0):0-1.

5. Katz DL, Meller S. Can we say what diet is best for health? Annu Rev Public Health [Internet]. 2014;35:83-103.

6. Liu RH. Health-promoting components of fruits and vegetables in the diet. Adv Nutr [Internet]. 2013 May [cited 2016 Oct 9];4(3):384S-92S.

7. Fardet A. Minimally processed foods are more satiating and less hyperglycemic than ultraprocessed foods: a preliminary study with 98 ready-to-eat foods. Food Funct [Internet]. 2016;7(Group 4):2338-46.

8. Foster-Powell K, Holt SHA, Brand-Miller JC. International table of glycemic index and glycemic load values: 2002. Am J Clin Nutr [Internet]. 2002;76(1):5-56.

9. Brand-Miller J, Buyken AE. The glycemic index issue. Curr Opin Lipidol [Internet]. 2012 Feb [cited 2016 Oct 9];23(1):62-7.

10. Hite AH, Berkowitz VG, Berkowitz K. Low-carbohydrate diet review: shifting the paradigm. Nutr Clin Pract Off Publ Am Soc Parenter Enter Nutr [Internet]. 2011;26(3):300-8.

11. Tobias DK, Chen M, Manson JE, Ludwig DS, Willett W, Hu FB. Effect of low-fat diet interventions versus other diet interventions on long-term weight change in adults: A systematic review and meta-analysis. Lancet Diabetes Endocrinol [Internet]. 2015;3(12):968-79.

12. $\mathrm{Hu} \mathrm{T}$, Bazzano LA. The low-carbohydrate diet and cardiovascular risk factors: evidence from epidemiologic studies. Nutr Metab Cardiovasc Dis [Internet]. 2014 Apr [cited 2016 Oct 9];24(4):33743. 
13. Lindeberg S, Berntorp E, Carlsson R, Eliasson M, Marckmann P. Haemostatic variables in Pacific Islanders apparently free from stroke and ischaemic heart disease--the Kitava Study. Thromb Haemost [Internet]. 1997;77(1):94-8.

14. Lindeberg S, Nilsson-Ehle P, Terent A, Vessby B, Schersten B. Cardiovascular risk factors in a Melanesian population apparently free from stroke and ischaemic heart disease: the Kitava study. J InternMed [Internet]. 1994;236(3):331-40.

15. Lindeberg S, Lundh B. Apparent absence of stroke and ischaemic heart disease in a traditional Melanesian island: a clinical study in Kitava. J Intern Med [Internet]. 1993;233(3):269-75.

16. Johnson A, Behrens C. Nutritional Criteria in Machiguenga Food Production Decisions: A Linear-Programming Analysis. Hum Ecol. 1982;10(2):167-89.

17. Masharani U, Sherchan P, Schloetter M, Stratford S, Xiao A, Sebastian A, et al. Metabolic and physiologic effects from consuming a hunter-gatherer (Paleolithic)-type diet in type 2 diabetes. Eur $\mathbf{J}$ Clin Nutr [Internet]. 2015;69(November 2014):1-5.

18. Otten J, Mellberg C, Ryberg M, Sandberg S, Kullberg J, Lindahl B, et al. Strong and persistent effect on liver fat with a Paleolithic diet during a two-year intervention. Int $\mathrm{J}$ Obes [Internet]. 2016;40(November 2015):1-28.

19. Jönsson T, Ahrén B, Pacini G, Sundler F, Wierup N, Steen S, et al. A Paleolithic diet confers higher insulin sensitivity, lower C-reactive protein and lower blood pressure than a cereal-based diet in domestic pigs. Nutr Metab (Lond) [Internet]. 2006;3:39.

20. Lindeberg S, Jonsson T, Granfeldt Y, Borgstrand E, Soffman J, Sjostrom K, et al. A Palaeolithic diet improves glucose tolerance more than a Mediterranean-like diet in individuals with ischaemic heart disease. Diabetologia [Internet]. 2007;50(9):1795-807.

21. Pastore R, Brooks J, Carbone J.W. Paleolithic nutrition improves plasma lipid concentrations of hypercholesterolemic adults to a greater extent than traditional heart-healthy dietary recommendations. Nutr Res. 2015; 35(6):474-79.

22. McDougall J, Thomas LE, McDougall C, Moloney G, Saul B, Finnell JS, et al. Effects of 7 days on an ad libitum low-fat vegan diet: the McDougall Program cohort. Nutr J [Internet]. 2014;13:99.

23. Zeevi D, Korem T, Zmora N, Israeli D, Rothschild D, Weinberger A, et al. Personalized Nutrition by Prediction of Glycemic Responses. Cell. 2015;163(5):1079-95.

24. Spreadbury I. Comparison with ancestral diets suggests dense acellular carbohydrates promote an inflammatory microbiota, and may be the primary dietary cause of leptin resistance and obesity. Diabetes, Metab Syndr Obes Targets Ther. 2012;5:175-89.

25. Spreadbury I, Samis AJW. Evolutionary Aspects of Obesity, Insulin Resistance, and Cardiovascular Risk. Curr Cardiovasc Risk Rep [Internet]. 2013;7(2):136-46.

26. Thaiss CA, Zmora N, Levy M, Elinav E. The microbiome and innate immunity. Nature [Internet]. 2016 Jul 7 [cited 2016 Oct 9];535(7610):65-74.

27. Backhed F, Ding H, Wang T, Hooper L V, Koh GY, Nagy A, et al. The gut microbiota as an environmental factor that regulates fat storage. Proc NatlAcadSciUSA [Internet]. 2004;101(44):1571823.

28. Schéle E, Grahnemo L, Anesten F, Hallén A, Bäckhed F, Jansson JO. Regulation of body fat mass by the gut microbiota: Possible mediation by the brain. Peptides [Internet]. 2016;77:54-9.

29. Schéle E, Grahnemo L, Anesten F, Halleń A, Bac̈khed F, Jansson JO. The gut microbiota reduces leptin sensitivity and the expression of the obesity-suppressing neuropeptides proglucagon (Gcg) and brain-derived neurotrophic factor (Bdnf) in the central nervous system. Endocrinology. 2013;154(10):3643-51.

30. Rosenbaum M, Knight R, Leibel RL. The gut microbiota in human energy homeostasis and obesity. Trends Endocrinol Metab [Internet]. 2015 Sep [cited 2016 Oct 9];26(9):493-501.

31. de Lartigue G. Role of the vagus nerve in the development and treatment of diet-induced obesity. J Physiol [Internet]. 2016;0:1-25. 
32. de Lartigue G, Barbier de la Serre C, Espero E, Lee J, Raybould HE. Diet-induced obesity leads to the development of leptin resistance in vagal afferent neurons. Am J Physiol Metab [Internet]. 2011;301(1):E187-95.

33. de Lartigue G, Ronveaux CC, Raybould HE. Deletion of leptin signaling in vagal afferent neurons results in hyperphagia and obesity. Mol Metab [Internet]. 2014;3(6):595-607.

34. Daly DM, Park SJ, Valinsky WC, Beyak MJ. Impaired intestinal afferent nerve satiety signalling and vagal afferent excitability in diet induced obesity in the mouse. J Physiol [Internet]. 2011;589(Pt 11):2857-70.

35. de La Serre CB, de Lartigue G, Raybould HE. Chronic exposure to Low dose bacterial lipopolysaccharide inhibits leptin signaling in vagal afferent neurons. Physiol Behav [Internet]. 2015;139:188-94.

36. Hamilton, M K; Boudry, G; Lemay, D G; Raybould HE. Changes in intestinal barrier function and gut microbiota in high-fat diet-fed rats are dynamic and region dependent. Am J Physiol Gastrointest Liver Physiol. 2015;308(10):G840-51.

37. Le Roy T, Llopis M, Lepage P, Bruneau A, Rabot S, Bevilacqua C, et al. Intestinal microbiota determines development of non-alcoholic fatty liver disease in mice. Gut [Internet]. 2013 Dec [cited 2016 Oct 9];62(12):1787-94.

38. Caesar R, Reigstad CS, Bäckhed HK, Reinhardt C, Ketonen M, Lundén GÖ, et al. Gut-derived lipopolysaccharide augments adipose macrophage accumulation but is not essential for impaired glucose or insulin tolerance in mice. Gut [Internet]. 2012 Dec [cited 2016 Oct 9];61(12):1701-7.

39. Llopis M, Cassard AM, Wrzosek L, Boschat L, Bruneau A, Ferrere G, et al. Intestinal microbiota contributes to individual susceptibility to alcoholic liver disease. Gut [Internet]. 2016 May [cited 2016 Oct 9];65(5):830-9.

40. Poutahidis T, Kleinewietfeld M, Smillie C, Levkovich T, Perrotta A, Bhela S, et al. Microbial Reprogramming Inhibits Western Diet-Associated Obesity. PLoS One. 2013;8(7):e68596.

41. Chassaing B, Koren O, Goodrich JK, Poole AC, Srinivasan S, Ley RE, et al. Dietary emulsifiers impact the mouse gut microbiota promoting colitis and metabolic syndrome. Nature [Internet]. 2015;519(7541):92-6.

42. Kaliannan K, Hamarneh SR, Economopoulos KP, Nasrin Alam S, Moaven O, Patel P, et al. Intestinal alkaline phosphatase prevents metabolic syndrome in mice. Proc Natl Acad Sci U S A [Internet]. 2013;110(17):7003-8.

43. Genton L, Cani PD, Schrenzel J. Alterations of gut barrier and gut microbiota in food restriction, food deprivation and protein-energy wasting. Clin Nutr [Internet]. 2015;34(3):341-9.

44. Lockhart PB, Bolger AF, Papapanou PN, Osinbowale O, Trevisan M, Levison ME, et al. Periodontal disease and atherosclerotic vascular disease: Does the evidence support an independent association?: A scientific statement from the American heart association. Circulation. 2012;125(20):2520-44.

45. Cutress TW. Dental caries in South Pacific populations: a review. Pac Health Dialog [Internet]. 2003;10(1):62-7.

46. Hujoel P, Diseases D. Dietary Carbohydrates and Dental-Systemic Diseases. J Dent Res. 2009;88(6):490-502.

47. Adler CJ, Dobney K, Weyrich LS, Kaidonis J, Walker AW, Haak W, et al. Sequencing ancient calcified dental plaque shows changes in oral microbiota with dietary shifts of the Neolithic and Industrial revolutions. Nat Genet [Internet]. 2013;45(4):450-5.

48. Zelkha SA, Freilich RW, Amar S. Periodontal Innate Immune Mechanisms Relevant to Atherosclerosis and Obesity. Periodontol 2000 [Internet]. 2010 Oct;54(1):207-21.

49. Hajishengallis G. Periodontitis: from microbial immune subversion to systemic inflammation. Nat Rev Immunol [Internet]. 2014;15(1):30-44.

50. Baumgartner S, Imfeld T, Schicht O, Rath C, Persson RE, Persson GR. The impact of the stone 
age diet on gingival conditions in the absence of oral hygiene. J Periodontol [Internet]. 2009 May [cited 2016 Oct 9];80(5):759-68.

51. Woelber JP, Bremer K, Vach K, König D, Hellwig E, Ratka-Krüger P, et al. An oral health optimized diet can reduce gingival and periodontal inflammation in humans - a randomized controlled pilot study. BMC Oral Health [Internet]. 2016;17(1):1-8.

52. Kentish SJ, Page AJ. The role of gastrointestinal vagal afferent fibres in obesity. J Physiol [Internet]. 2015;593(4):775-86.

53. Aidy S El, van den Bogert B, Kleerebezem M. The small intestine microbiota, nutritional modulation and relevance for health. Curr Opin Biotechnol [Internet]. 2015;32:14-20.

54. Gury-BenAri M, Thaiss CA, Serafini N, Winter DR, Giladi A, Lara-Astiaso D, et al. The Spectrum and Regulatory Landscape of Intestinal Innate Lymphoid Cells Are Shaped by the Microbiome. Cell [Internet]. 2016 Aug 25 [cited 2016 Oct 9];166(5):1231-1246.e13.

55. Mann T, Tomiyama AJ, Westling E, Lew AM, Samuels B, Chatman J. Medicare's search for effective obesity treatments: diets are not the answer. Am Psychol [Internet]. 2007;62(3):220-33.

56. Farias MM, Cuevas AM, Rodriguez F. Set-point theory and obesity. Metab Syndr Relat Disord [Internet]. 2011;9(2):85-9.

57. Jönsson T, Granfeldt Y, Lindeberg S, Hallberg A-C. Subjective satiety and other experiences of a Paleolithic diet compared to a diabetes diet in patients with type 2 diabetes. Nutr $\mathrm{J}$ [Internet]. 2013;12:105.

58. Jönsson T, Granfeldt Y, Erlanson-Albertsson C, Ahrén B, Lindeberg S, Jonsson T, et al. A paleolithic diet is more satiating per calorie than a mediterranean-like diet in individuals with ischemic heart disease. Nutr Metab [Internet]. 2010;7(1):85.

59. Frassetto LA, Schloetter M, Mietus-Synder M, Morris Jr. RC, Sebastian A. Metabolic and physiologic improvements from consuming a paleolithic, hunter-gatherer type diet. Eur J Clin Nutr [ 